\title{
Research on Helium Mass-spectrometer Back Pressure Leak Detection Purification Craft for the Specimen with Epoxy Resin
}

\author{
Yingjun Huang ${ }^{a}$, Xudong Liao ${ }^{b}$, Guoyun Baic ${ }^{\mathrm{c}}$, Bo Lid ${ }^{\mathrm{d}}$, Miao Lou ${ }^{\mathrm{e}}$ \\ The North-West Institute of Nuclear Technology, Xi'an 710024, China \\ ahuangjun888500@163.com, b511851318@qq.com, cbaiguoyun2010@sohu.com, \\ d13157590021@163.com, 'Toumiao531@yahoo.com.cn,
}

Keywords: Epoxy resin; Surface cleaning technology; Back pressure leak detection; The maximum dwell time.

\begin{abstract}
The purification effect of the blow wash method, low thermal air blow wash method, vacuum method and alcohol cleaning + blow wash method for helium mass-spectrometer back pressure leak detection were researched and compared. It is found that these four purification craft will not accelerate the helium loss in the specimen. To the specimen with epoxy resin, if the maximum dwell time is short, the low thermal air blow wash method or alcohol cleaning + blow wash method will be befitting, and if the maximum dwell time is enough, the vacuum method can be the best choice.
\end{abstract}

\section{Introduction}

The key points of helium mass-spectrometer back pressure leak detection purification crafts are cleaning the specimen in the short time, and making the helium loss in the acceptable range $[1,2]$. In some project, the leak detection connector of specimen was welded after the helium mass-spectrometer leak detection, and the best method to detect the sealability of the welding line is helium mass-spectrometer back pressure leak detection [3]. For some special reason, we can't weld the metal gas-collecting skirt on the specimen, so the epoxy resin was selected. According to the steps of the back pressure leak detection, the surface of the welding line, gas-collecting skirt and the epoxy resin should be purified after pressing. Now, the common purification crafts to the metal are baking out method, ion beam bombardment method, electron beam bombardment method, et al [4]. The purification principles of these methods are making the molecule on the surface or atom in the metal released by heating the specimen, which is not suitable for epoxy resin. According to these problems, the suitable purification crafts for epoxy resin will be researched in this article.

The epoxy resin we used has low thermal stability, high mechanical strength good alcohol tolerance but high gas adsorption [5]. According to these physical and chemical properties, five purification crafts were selected, which were standing method, blow wash method, low thermal air blow wash method, vacuum method and alcohol cleaning + blow wash method.

\section{Theoretical Analysis}

2.1 The Influence of Purification Craft to the Helium Pressure in the Specimen. The purification effect was judged by experimental data, and the helium loss in the specimen could be judged by theoretical analysis. When the leak rate of specimen is less than $5 \times 10^{-6} \mathrm{~Pa} \cdot \mathrm{m}^{3} / \mathrm{s}$, the leak gas will be molecular flow [1]. According to the back pressure leak detection theoretical formula, when the pressure time is $t_{1}$, the helium pressure in the specimen can be formulated as

$$
p_{1}=p_{E}\left[1-\exp \left(-\frac{K t_{1}}{V \sqrt{M}}\right)\right]
$$

where $p_{\mathrm{E}}$ is the helium pressure in the pressurized room, $V$ is the internal volume of the specimen, $M$ is the molar ratio of helium, $K$ is the constant about leak size and temperature. After standing for $t_{2}$, the helium pressure in the specimen drop from $p_{1}$ to $p_{2}$, and the helium leak formula can be formulated as 


$$
\begin{aligned}
& V \frac{\mathrm{d} p}{\mathrm{~d} t}=\frac{K}{\sqrt{M}}(0-p) \\
& p_{2}=p_{1} \exp \left(-\frac{K t_{2}}{V \sqrt{M}}\right)
\end{aligned}
$$

As the formula shown, the helium pressure in the specimen is $p$, during the blow wash process and vacuum process, and 0 outside the specimen, they have the same helium concentration difference, and fit the formula (2) both, the $p_{2}$ is same. Therefore, the blow wash process and vacuum process will not accelerate the loss of helium inside as the standing method. The low thermal air blow wash method will accelerate the loss of helium inside slightly for the short heating time, low temperature and high thermal conductivity. The alcohol cleaning process will reduce the helium leak and improve the test accuracy for plugging the leakage hole. Thus these four methods will not accelerate the loss of helium in the specimen obviously, we should take the surface purification effect into account only. The final relationship between test leak rate and equivalent standard leak rate can be formulated as

$$
Q_{R}=\frac{Q_{L} p_{E}}{p_{0}} \sqrt{\frac{M_{A}}{M}}\left[1-\exp \left(-\frac{Q_{L} t_{1} \sqrt{\frac{M_{A}}{M}}}{V p_{0}}\right)\right] \exp \left(-\frac{Q_{L} t_{2} \sqrt{\frac{M_{A}}{M}}}{V p_{0}}\right)
$$

Where $Q_{\mathrm{R}}$ is test leak rate, $Q_{\mathrm{L}}$ is equivalent standard leak rate, $p_{0}$ is standard atmospheric pressure, $M_{A}$ is the molar ratio of atmosphere.

2.2 Make Sure the Maximum Dwell Time. The maximum dwell time of purification process is concerned with $V, p_{E}, t_{1}$ and refuse condition. Suppose the minimum detectable equivalent standard leak rate is $1.0 \times 10^{-5} \mathrm{~Pa} \cdot \mathrm{m}^{3} / \mathrm{s}$ and $V=20 \mathrm{ml}$ when the specimen is coarse detected. In order to control the error from the purification process to the test leak rate in $5 \%$, this condition must be appeased [6, 7]

$$
\exp \left(-\frac{Q_{20} t_{2} \sqrt{\frac{M_{A}}{M}}}{V p_{0}}\right)>0.95
$$

By the calculation, when $t_{2}<2700 \mathrm{~s}=45 \mathrm{~min}$, the error of test leak rate will less than $5 \%$ to specimen which $Q_{L}<1.0 \times 10^{-5} \mathrm{~Pa} \cdot \mathrm{m}^{3} / \mathrm{s}$

\section{Experiment}

The purification crafts standing method, blow wash method, low thermal air blow wash method, vacuum method and alcohol cleaning + blow wash method were expressed as 1\#, 2\#, 3\#, 4\# and 5\#. Use the homemade pressure-vacuum device to realize the pressure and vacuum of the specimen. The surface helium signal was test by L200+ helium mass-spectrometer leak detector from Oerlikon Leybold Vacuum Co., Ltd German and the signal of standing method was the reference object. According to the previous research, the $t_{1}$ is $24 \mathrm{~h}$, the pressure is $0.5 \mathrm{MPa}$. The blow wash method was using the $\mathrm{N}_{2}$ to clean the surface with the discharge pressure $0.2 \mathrm{MPa}$. The low thermal air blow wash method was using the adjustable hot air generator. The vacuum method was using the $3 \mathrm{~L} / \mathrm{s}$ vacuum pump. The purification time was $40 \mathrm{~min}$ all. It was found that the stable surface helium signal should be test for almost $2 \mathrm{~min}$ by suction gun, and could not test the signal continuously, therefore, the test cycle was set as $5 \mathrm{~min}$, the specific process was shown in Table 1. 
Table 1 The purification craft parameter

\begin{tabular}{rccl}
\hline Num & $\begin{array}{c}\text { Pressure } \\
\text { parameter }\end{array}$ & $\begin{array}{c}\text { Purification } \\
\text { time }\end{array}$ & \multicolumn{1}{c}{ Purification step } \\
\hline $1 \#$ & & & Test the signal per $5 \mathrm{~min}$. \\
$2 \#$ & & Blow the surface for $3 \mathrm{~min}$ by $\mathrm{N}_{2}$, and test for $2 \mathrm{~min}$. \\
$3 \#$ & $24 \mathrm{~h}$ & $40 \mathrm{~min}$ & $\begin{array}{l}\text { Heat the surface for } 3 \mathrm{~min} \text { at } 50^{\circ} \mathrm{C}, \text { and test for } 2 \mathrm{~min} . \\
\text { Vacuum for } 3 \mathrm{~min}, \text { and test for } 2 \mathrm{~min} .\end{array}$ \\
$4 \#$ & $0.5 \mathrm{MPa}$ & & $\begin{array}{l}\text { Steep the specimen in alcohol for } 2 \mathrm{~min}, \text { and blow the } \\
\text { surface for } 3 \mathrm{~min} \text { by } \mathrm{N}_{2}, \text { than test for } 2 \mathrm{~min} .\end{array}$ \\
$5 \#$ & & & \\
& &
\end{tabular}

\section{Results and Analysis}

The test data of different purification crafts was shown in Fig.1, all the data had removed the system background signal.

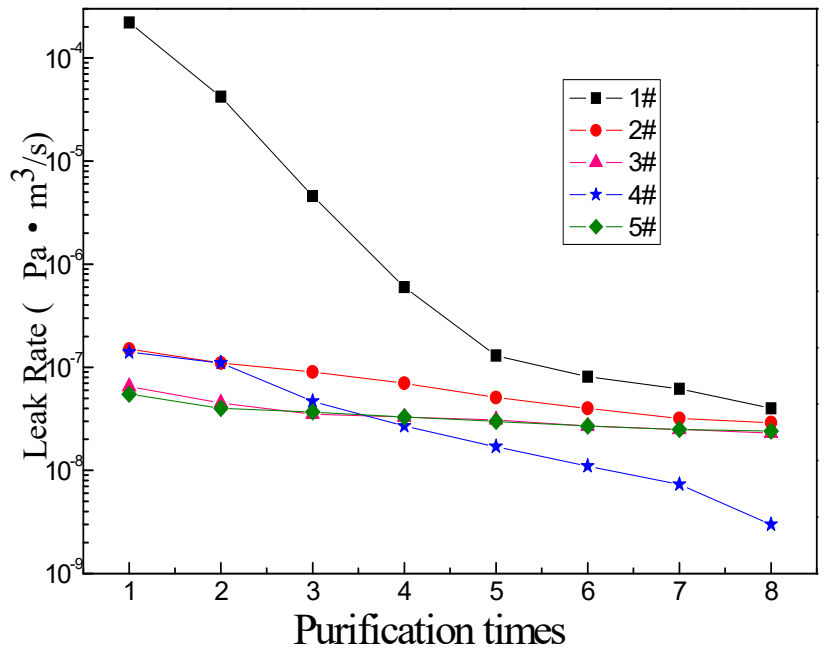

Fig.1 The surface helium signal curve of different purification craft

As the Fig.1 shown, the purification craft of other four methods were better than standing method, especially in the beginning five cycles. At the $6^{\text {th }}$ test $(30 \mathrm{~min})$, the surface helium signal had reduced to $10^{-8} \mathrm{~Pa} \cdot \mathrm{m}^{3} / \mathrm{s}$ by standing method. At the early purification, the alcohol cleaning + blow wash method and low thermal air blow wash method had the fastest purification effect, which could reduced the surface helium signal to $10^{-8} \mathrm{~Pa} \cdot \mathrm{m}^{3} / \mathrm{s}$ at $5 \mathrm{~min}$, than the blow wash method and vacuum method. After the $4^{\text {th }}$ test $(20 \mathrm{~min})$, the advantages of the vacuum method exerted, became to the fastest purification craft, and reduced the surface helium signal to $3.0 \times 10^{-9} \mathrm{~Pa} \cdot \mathrm{m}^{3} / \mathrm{s}$ at $8^{\text {th }}$ test (40min). The purification effect of the alcohol cleaning + blow wash method and low thermal air blow wash method was similar, and better than blow wash method both. The forming reasons of these purification craft's feature were shown in Table 2.

Table 2 The forming reason of these purification rules

\begin{tabular}{ccc}
\hline Num & Name & The forming reason of the purification rule \\
\hline $2 \#$ & $\begin{array}{c}\text { Blow wash } \\
\text { method }\end{array}$ & $\begin{array}{c}\text { The } \mathrm{N}_{2} \text { could clean the helium on the surface only, to the helium in the epoxy } \\
\text { resin, it was useless. }\end{array}$ \\
$\begin{array}{c}\text { Low thermal } \\
\text { air blow wash } \\
\text { method, }\end{array}$ & $\begin{array}{c}\text { When the epoxy resin was heated, the helium on the surface and in the epoxy } \\
\text { resin got additional momentum, and moved faster, which accelerated the stripping } \\
\text { of helium. Therefore, the purification effect was better than the blow wash method. }\end{array}$
\end{tabular}


At the early purification process, the purification effect of vacuum method was worse than the blow wash method, but latterly, the blow wash method could not clean the helium in the epoxy resin effectively, while the vacuum method could provide pressure difference and concentration difference, which were good for helium's desorption. Therefore, the vacuum method had the best purification effect.

Alcohol cleaning + Blow wash method

After washing by the alcohol, the helium would accelerate the desorption for the volatilization of the alcohol when washed by $\mathrm{N}_{2}$, which made the purification effect good at early purification process. However, it could not clean the helium effectively in the epoxy resin by volatilization, and the final effect was not ideal.

\section{Summary}

In conclusion, these four purification craft had better effect to the helium on the epoxy resin, would not accelerate the loss of the helium in the specimen and affect the accuracy of measurement results. If the maximum dwell time is short, the low thermal air blow wash method or alcohol cleaning + blow wash method can get good effect at short time. If the maximum dwell time is long enough, the longtime vacuum method can get the best effect.

\section{References}

[1] Wu Xiao-jian, Yan Rong-xin. Leak Detection [M]. Beijing: China Machine Press, 2013:102-108.

[2] Xue Da-tong, Xiao Xiang-zheng, Li Hui-juan, et al. Modification of Inside-out Leak-testing Technique with Mass Spectrometer Leak-detector [J]. Chinese Journal of Vacuum Science and Technology, 2011, 38(1): 105-109.

[3] GJB/Z221-2005 Guideline for the Practice of Leak Detection Method for Sealed Military Parts[S].

[4] Zhang Yi-chen. Vacuum Technology and Experimental Technology[M]. Beijing: Metallurgical Industry Press, 2006: 76-96.

[5] Wang Hong-wei. On Features of Epoxy Resin and Its General Application [J]. Shanxi Architecture, 2011, 37(35): 114-116.

[6] Wang Geng-lin, Li Fei, Wang Cai-yi, et al. Base Criterion and Maximum Dwell Time of Fine Leak Test Using the Helium Mass Spectrometer Leak Detector [J]. Journal of CAEIT, 2013, 8(2): 213-220.

[7] Wang Geng-lin, Wang Cai-yi, Wang Li-yan, et al. The Modification of the GJB Helium Mass Spectrometer Fine Leak Test [J]. Electronic Product Reliability and Environment Test, 2009(B10): 21-32. 